\title{
A EDUCAÇÃO FÍSICA NA ESCOLARIZAÇÃO DA PEQUENA INFÂNCIA*
}

\author{
Marynelma Camargo Garanhani**
}

\begin{abstract}
RESUMO
Com a intenção de apresentar reflexões e proposições sobre a Educação Física na escolarização da criança de zero a seis anos apresentamos este estudo que se organiza em dois momentos distintos. No primeiro momento, desenvolvemos reflexões sobre o movimento corporal da criança no seu processo de aquisição e construção de conhecimentos, com base nos estudos de Wallon. No segundo momento, sistematizamos proposições para um encaminhamento pedagógico da Educação Física no âmbito da educação infantil.

PALAVRAS-CHAVE: Educação infantil - Movimento corporal - Educação Física escolar.
\end{abstract}

\section{INTRODUÇÃO}

$\mathrm{E}^{\mathrm{n}}$ $m$ virtude da escassez de discussões que possibilitem maior aprofundamento em relação às implicações pedagógicas da Educação Física, no âmbito da educação infantil, ${ }^{1}$ destacamos inicialmente a necessidade de pesquisas nessas áreas.

Em uma análise sobre o estado do conhecimento da motricidade na produção teórica da educação infantil no Brasil durante o período de 1983 a 1998 - observamos uma baixa produção de artigos científicos (seis), dissertações (trinta) e teses (uma), na área da educação, que abordassem o movimento do corpo infantil na escolarização da pequena infância (Garanhani, 2000). A pesquisa revelou, também, que os referidos estudos abordam o tema

* A expressão "pequena infância" refere-se ao período de zero a seis anos.

* * Professora do Departamento de Educação Física da UFPR, mestre em Educação e doutoranda em Psicologia da Educação na PUC-SP. Email:marynelma@avalon.sul.com.br.

106 GARANHANI, M. C. A educação física na escolarização da pequena infância 
sob diferentes formas. Em alguns estudos este é tratado como orientação metodológica para a aprendizagem infantil e, em outros, como uma atividade física necessária ao desenvolvimento da criança. $\mathrm{Na}$ forma de conteúdo escolar, os estudos tratam o movimento do corpo infantil no âmbito da Educação Física e se apresentam em número menor ao serem comparados com as pesquisas que utilizam outras formas de abordagens. Esses dados podem ser atribuídos a uma fragilidade de identificação e definição da educação infantil como pertinente à instituição escolar, conseqüentemente, a uma indefinição sobre os elementos que compõem essa fase de escolarização e sobre o modo como se organizam.

Tendo como pressuposto que a instituição de educação infantil vincula a dimensão do cuidar à do educar, pesquisadores ${ }^{2}$ sobre a educação da pequena infância no Brasil propõem a transformação das instituições que lidam com ela em um nível de ensino: a primeira etapa da educação básica - conforme a orientação da nova Lei de Diretrizes e Bases da Educação Nacional (LDB), de 1996 -, mas sem reproduzir ou trazer para essas instituições as práticas desenvolvidas no ensino fundamental. Cerisara (1999, p. 16) nos alerta que para enfrentar esse desafio

... é preciso ter claro que o trabalho junto às crianças em creches e préescolas não se reduz ao ensino de conteúdos ou disciplinas, ou de conteúdos escolares que reduzem e fragmentam o conhecimento, mas implica trabalhar com as crianças pequenas em diferentes contextos educativos, envolvendo todos os processos de constituição da criança em suas dimensões intelectuais, sociais, emocionais, expressivas, culturais, interacionais.

Cerisara (1999 e 2000) ainda nos lembra que as funções de educar e cuidar de forma indissociável e complementar, atribuídas às instituições de educação infantil, são relativamente recentes na história da educação, e esse fato gerou a necessidade de (re)pensar a escola da pequena infância.

Nesse contexto educacional, os estudos na área da Educação Física escolar deverão se preocupar em discutir e apresentar elementos teóricos e metodológicos para uma concepção de educação 
infantil que valorize e sistematize o movimento corporal da criança, no seu processo de apropriação da cultura e na construção do seu pensamento.

Com o intuito de contribuir com esse cenário, nosso texto se divide em dois diferentes momentos. Inicialmente abordamos o movimento corporal da criança, no seu processo de aquisição e construção de conhecimentos, e, no segundo momento, apresentamos proposições sistematizadas para um encaminhamento pedagógico da Educação Física no âmbito da educação infantil. Apesar de esses momentos terem se constituído de forma independente, o objetivo é que na leitura dos textos estes se integrem e provoquem reflexões sobre a Educação Física na escolarização da pequena infância.

\section{O MOVIMENTO CORPORAL DA CRIANÇA NO PROCESSO DE AQUISIÇÃO E CONSTRUÇÃO DE CONHECIMENTOS}

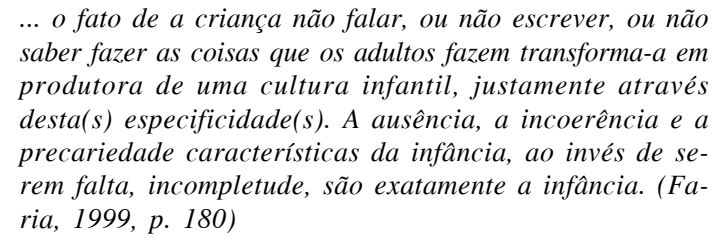

... o fato de a criança não falar, ou não escrever, ou não saber fazer as coisas que os adultos fazem transforma-a em produtora de uma cultura infantil, justamente através desta(s) especificidade(s). A ausência, a incoerência e a precariedade características da infância, ao invés de serem falta, incompletude, são exatamente a infância. (Faria, 1999, p. 180)

Para situar alguns indicadores teóricos acerca do movimento corporal da criança no seu processo de aquisição e construção de conhecimentos, recorremos aos estudos da psicologia justificando essa escolha na introdução de um dos estudos de Cerisara (2000, p. 79) sobre a educação da pequena infância.

... recorro à psicologia por entender que a educação é uma prática social que precisa das outras áreas de conhecimento para fundamentar o seu fazer pedagógico. A psicologia é uma entre tantas outras áreas de conhecimento, tais como a sociologia, a antropologia, a história, a lingüística, que têm instrumentalizado os educadores na tentativa de compreender a complexidade das relações que se estabelecem, de um lado, entre a escola e a sociedade entendida em seu sentido mais amplo e, de outro, entre os agentes sociais envolvidos no processo educacional den- 
tro da instituição escolar propriamente dita: pais, crianças, professores, diretores, pajens, educadores, profissionais etc.

Apesar de entender que os estudos da psicologia são fundamentais para a educação, acreditamos que nenhuma teoria psicológica por si só seja capaz de dar conta das múltiplas faces do processo educativo da criança pequena, ou de explicar e resolver os problemas existentes na prática pedagógica da educação infantil.

Cerisara (2000) nos afirma que, ao eleger uma área de conhecimento para fundamentar o fazer pedagógico, é necessário estabelecer múltiplas relações da área eleita com outras áreas de conhecimento e, também, com outras teorias da mesma área. Esse procedimento se torna importante na medida em que ameniza um dos problemas que tem atingido, diretamente, a educação infantil:

os tais modismos pedagógicos que pecam exatamente por absolutizar uma teoria, em geral teorias psicológicas, tomando-a como capaz de explicar e resolver todos os problemas que a prática pedagógica apresenta. (Cerisara, 2000, p. 79)

É importante dizer que não temos a intenção de discorrer, neste texto, a respeito dos modismos presentes na educação infantil. Abordamos essa problemática com o intuito de esclarecer a escolha dos estudos da psicologia para fundamentar as reflexões que apresentamos e de mostrar os procedimentos que as nortearam.

Na pequena infância o corpo em movimento constitui a matriz básica da aprendizagem pelo fato de gestar as significações do aprender, ou seja, a criança transforma em símbolo aquilo que pode experimentar corporalmente, e seu pensamento se constrói, primeiramente, sob a forma de ação.

A criança pequena necessita agir para compreender e expressar os significados presentes no contexto histórico-cultural em que se encontra. Wallon (1979) ressalta que na pequena infância o ato mental se desenvolve no ato motor, ou seja, a criança pensa na ação e isso faz que o movimento do corpo ganhe um papel de destaque nas fases iniciais do desenvolvimento infantil. Mas como isso ocorre? 
Wallon (1942) nos diz que o homem é um ser biologicamente social $^{3}$ e que é na complexa dinâmica de cada cultura que ocorre o seu desenvolvimento. Nesse processo, o movimento do corpo se apresenta como um dos campos funcionais, e integrado com a afetividade e a inteligência, constitui a pessoa como um todo.

Tendo em conta a historicidade do meio humano, Wallon concebe, pois, a ontogênese como uma sucessão de modos de relação com diferentes meios em função dos meios funcionais de que dispõe cada idade em cada microcultura. (Werebe e Nadel-Brulfert, 1999, p. 19)

Para Wallon, citado por Mahoney (2000), cada um dos campos funcionais (o motor, o afetivo, o cognitivo e a pessoa que integra todos os outros) apresenta uma identidade estrutural e funcional diferenciada. Mas esses campos estão de tal forma integrados que cada um é parte constitutiva dos outros, de modo que a separação se faz necessária somente para a descrição do processo de desenvolvimento. Pela lei da predominância funcional, ${ }^{4}$ cada um deles predomina em um estágio do desenvolvimento, e eles se nutrem mutuamente, sendo que o exercício e o amadurecimento de um interfere no amadurecimento dos outros (Mahoney, 2000).

O campo funcional motor, nas fases iniciais do desenvolvimento infantil, integra a criança no seu contexto histórico-cultural, e é por intermédio dele que ela começa a organizar a sua compreensão sobre as coisas e sobre como essas se encontram no espaço, bem como as relações com as pessoas presentes nesse contexto.

Wallon, citado por Mahoney (2000), ao descrever o processo do desenvolvimento infantil, ressalta que a criança, já no início do seu desenvolvimento, estabelece uma relação de comunicação com o meio, através da seleção de movimentos do corpo que garantem a sua aproximação do outro e a satisfação de suas necessidades. Portanto, na fase inicial do desenvolvimento infantil, os movimentos do corpo se apresentam como instrumentos expressivos de bemestar e mal-estar.

Conforme o desenvolvimento avança, a relação da criança com o meio facilita a discriminação das formas de se comunicar, sendo que o andar e a linguagem desencadeiam um salto qualitati-

110 GARANHANI, M. C. A educação física na escolarização da pequena infância 
vo no desenvolvimento da pequena infância, possibilitando uma maior autonomia e independência na investigação do espaço e dos objetos, que nele se encontram e o organizam.

Os objetos e a organização do espaço constituem, nesse momento, uma oportunidade ou ocasião de movimentação e exploração do corpo, e essa constatação propicia estudos e discussões pedagógicas sobre o material educativo na escola da pequena infância. A exploração corporal é extremamente dependente do grau de atratividade do espaço e dos objetos que nele se encontram e o organizam. Por esses motivos, tanto quanto possível devem ser considerados, na seleção do material educativo para a escola da pequena infância, os aspectos de natureza estética (tamanhos, cores e formas), mas também os que possibilitam diferentes experiências e diversas formas de se movimentar.

No processo de desenvolvimento da criança pequena, o andar e a linguagem proporcionam ainda o ingresso no mundo dos símbolos, enfatizando Wallon (1942) que é na idade de dois a três anos (etapa projetiva) que a criança conquista a dimensão simbólica do pensamento, e isso lhe dará condições de se apropriar do conhecimento cultural acumulado, historicamente, pelo meio social.

A capacidade de simbolização se inicia quando a criança começa a imitar ${ }^{5}$ o que vê ao redor e a expressar o seu pensamento por ideomovimentos - pensamento apoiado em gestos -, o que lhe possibilita ultrapassar os limites sensório-motores do comportamento.

O gesto é capaz de tornar presente o objeto e substituí-lo, ou seja, pelos gestos a criança simula uma situação de utilização do objeto sem tê-lo, de fato, presente; trata-se de um ato sem o objeto real. [...] Essa atividade em que o faz-de-conta se faz presente consiste, portanto, na descoberta e no exercício do desdobramento da realidade, pressupondo o início da representação. [...] O desdobramento da realidade só será possível, no entanto, quando houver a subordinação da atividade sensório-motora à representação. Nesse momento, assiste-se ao início da organização do pensamento; a criança é capaz de dar significação ao símbolo e ao signo, ou seja, encontrar para um objeto sua representação e para a representação um signo. (Costa, 2000, p. 35) 
Mas, para a criança constituir a imagem e representá-la é preciso antes conhecer e estabelecer relações corporais com o objeto e/ ou a situação que será representada, sendo que a capacidade de simbolizar se amplia quando a criança articula a aquisição da fala, a manipulação de diferentes objetos e/ou vivências corporais de situações diferenciadas. Nesse cenário, a linguagem é o instrumento que vai elaborar e organizar a expressividade da criança no mundo dos símbolos, e o corpo, na condição de ser físico, afetivo, histórico e social, assume um papel fundamental no processo de constituição da criança pequena como sujeito ${ }^{6}$ cultural, pois esta também é produtora de cultura - uma cultura infantil.

Assim, os movimentos do corpo, tão importantes no desenvolvimento físico-motor infantil, também constituem uma linguagem que se constrói no processo histórico-cultural do meio onde a criança se encontra.

Isso nos leva a (re)pensar uma concepção de educação infantil que valorize o movimento corporal da criança não somente como uma necessidade físico-motora do seu desenvolvimento, mas também como uma capacidade expressiva e intencional.

$\mathrm{Na}$ pequena infância, a capacidade de brincar otimiza o desenvolvimento físico-motor da criança e propicia uma relação com os símbolos que constituem as atividades do seu cotidiano; portanto, o brincar oferece à criança condições de se desenvolver e se apropriar de elementos da realidade por meio da compreensão dos seus significados. Essas considerações nos levam a concluir que a escola da pequena infância é um espaço, por excelência, de aprendizagens que envolvem movimentos corporais, e o brincar é um princípio que norteia, pedagogicamente, o seu cotidiano.

Assim, a escolarização da pequena infância, ao proporcionar o desenvolvimento infantil nas suas diversas dimensões, realiza a mediação entre a criança e o conhecimento culturalmente construído e traduzido em diferentes formas de linguagem (oral, corporal, musical, gráfico-pictórica e plástica). Ao mesmo tempo, desenvolve na criança habilidades para a expressão e a comunicação. Mas, para que esse processo ocorra, é necessário estar atento ao cotidiano da educação infantil, o qual deverá contemplar no seu fazer pedagógico as diferentes linguagens, e essa condição está diretamente atrela-

112 GARANHANI, M. C. A educação física na escolarização da pequena infância 
da à formação do educador responsável pela escolarização dessa idade.

Machado (1998), em seus estudos sobre a formação profissional para a educação infantil, ressalta que no desenvolvimento de competências específicas para o cuidado/educação da criança pequena devem ser contemplados conteúdos sob as diferentes formas que ela - a criança - utiliza para a apropriação e construção de conhecimentos. Destacamos dentre essas formas o movimento corporal.

\section{EDUCAÇÃO FÍSICA INFANTIL: PROPOSIÇÕES PARA UM ENCAMINHAMENTO PEDAGÓGICO NA ESCOLARIZAÇÃO DA PEQUENA INFÂNCIA}

Pensar sobre a Educação Física no âmbito da educação infantil é sempre um desafio devido à maneira como essa fase da educação escolar, historicamente, se organizou e se organiza nos dias de hoje.

A educação infantil, atualmente, ao buscar uma especificidade em relação aos outros níveis de escolarização que a sucedem - devido às características e necessidades de cuidado/educação da pequena infância -, procura estruturar o seu conhecimento de forma diferente quando comparada à organização dos conteúdos escolares tradicionais (como a matemática, as ciências, a educação física etc). Essa organização diferenciada constitui um dos desafios da atual educação infantil.

Observamos em recentes estudos e documentos ${ }^{7}$ na área da educação infantil, em diferentes países, uma organização pedagógica baseada em campos ou âmbitos de experiência conforme as características e necessidades da idade infantil. São abordagens comuns nesses documentos a formação pessoal e social, e o conhecimento do mundo, através da apropriação de diferentes linguagens como formas de expressão e comunicação. Dentre essas formas, os documentos incluem os movimentos do corpo e apresentam diversas maneiras de organizá-los e nomeá-los. Na Itália eles apresentam a expressão "o corpo e o movimento" como um campo de experiência (Faria,1995). Em Portugal, o documento denominado Orienta- 
ções curriculares para a educação pré-escolar (Portugal, 1997) organiza os movimentos do corpo em expressão motora, dramática, plástica e musical. Estes constituem a área denominada "expressão e comunicação". O Referencial curricular nacional para a educação infantil (Brasil, 1998) apresenta a expressão "movimento", e este constitui um eixo de trabalho do âmbito de experiência "conhecimento do mundo". Assim, observa-se que a expressão "educação física" não está presente nos atuais documentos sobre as orientações curriculares para a educação infantil, apesar de haver uma valorização do corpo e seu movimento. Essas constatações sugerem estudos sobre a constituição e a organização histórica da Educação Física nos currículos educacionais referentes à pequena infância.

Em um estudo sobre a escolarização do corpo infantil ${ }^{8}$ observamos que a necessidade da Educação Física para a infância e conseqüentemente a expressão "educação física", surgiram no século XVIII, devido à preocupação dos pensadores da época com a conservação da criança. Portanto, é no século XVIII que a educação passa a ocupar o primeiro plano na sociedade, e a educação da infância torna-se uma prioridade dos seus pensadores, dentre eles Rousseau e Locke. Na sequiência ocorre, no século XIX, a criação e a institucionalização dos jardins de infância por Froebel. Este, ao perceber as vantagens intelectuais e morais dos jogos infantis para além do desenvolvimento físico, utiliza-os na educação da pequena infância como um princípio metodológico.

Nesse momento histórico, os jogos e os brinquedos infantis tomam um lugar de destaque na educação da pequena infância, e a tendência lúdico-espontânea que norteava a educação infantil passa também a nortear a educação física da criança. No final do século XIX e início do século XX, ocorre em vários países europeus uma expansão de experiências pedagógicas inovadoras para a educação da infância, com base nos estudos científicos de características biológicas e psicológicas. Dentre elas se destacaram o método montessoriano na Itália e as propostas pedagógicas de Decroly na Bélgica, os quais valorizavam os movimentos do corpo na educação sensorial e intelectual da infância. Nessa época, os movimentos corporais passam a ter um lugar de destaque nas orientações

114 GARANHANI, M. C. A educação física na escolarização da pequena infância 
curriculares da educação infantil, com o objetivo de dar suporte para a aquisição e o domínio das linguagens oral e escrita. Após a Primeira Guerra Mundial, no século XX, ocorrem significativas discussões sobre o cuidado, a preservação e a preparação da infância. Mas é somente após a Segunda Guerra Mundial que surge um movimento de valorização e de expansão do atendimento escolar à criança pequena, assumindo esse movimento um caráter de assistência social devido ao trabalho feminino.

... as transformações profundas na escolarização da infância ocorreram nos anos 60, desencadeadas, segundo Kramer (1987) e Spodek e Brown (1996), por uma série de fatores sociais, políticos, econômicos e ideológicos, sendo um deles o interesse renovado da comunidade científica sobre o papel do meio no desenvolvimento humano. Nessa época, as pesquisas que tinham como tema a educação infantil estavam centradas nos estudos do pensamento da criança e da influência da linguagem no rendimento escolar. Em decorrência destes fatos, os anos 70 constituíram-se nos anos pródigos em currículos e programas educativos para a criança e desencadearam, nos anos posteriores, pesquisas sobre as formas de fazer e de pensar a educação da pequena infância. (Garanhani e Moro, 2000, p. 117)

A Educação Física, nessas propostas pedagógicas, se constituiu e ainda se apresenta, nos dias atuais, de forma diversa, sob a influência e orientação de diferentes tendências, analisadas pelo Grupo de Estudos Ampliados em Educação Física(1996), como a recreação, a psicomotricidade e o desenvolvimento/aprendizagem motora. Tal situação nos leva a concluir que essas tendências sejam o reflexo das variadas concepções educativas que estiveram e estão presentes na prática pedagógica da educação infantil. Cerizara (2000) delineia essas concepções em três grandes tendências: a que pretende compensar as carências supostamente existentes nas crianças (concepção assistencialista); a que deseja recrear as crianças para que espontânea e naturalmente aprendam pelo convívio social e lúdico com outras (concepção recreacionista), apresentando ambas o objetivo de guarda e proteção; e, ainda, a de caráter antecipatório, que pretende preparar a criança para o ensino fundamental, com o objetivo instrucional. Cerizara (2000) nos informa ainda de que foi 
diante dessas concepções e contra elas que surgiu a defesa da função pedagógica da educação infantil, e é nessa direção que estão surgindo, nos dias atuais, orientações e novas propostas curriculares para essa educação.

Constatamos que, apesar de não se utilizar a expressão "educação física" para nomear um campo de experiência ou um eixo do trabalho pedagógico, há uma preocupação com a concepção de educação infantil que valoriza o movimento do corpo como expressão e comunicação, considerando-o como uma forma de linguagem que sistematiza e traduz as manifestações e práticas corporais construídas, culturalmente, no meio social. Não temos, porém, a pretensão de aprofundar considerações teóricas e reflexões sobre esse cenário. A breve e superficial apresentação histórica da constituição e organização da disciplina na escolarização da pequena infância teve como objetivo mostrar algumas suposições que justificam a não-utilização da expressão "educação física" no âmbito das atuais orientações e propostas curriculares para a educação infantil.

Ao buscar proposições pedagógicas com base no modelo histórico-cultural do desenvolvimento humano, pensamos que essa expressão delimita, ou melhor, limita o fazer pedagógico aos movimentos do corpo infantil. Ela dá ênfase apenas à educação do físico e não a uma educação que envolva, também, a compreensão e o domínio pela criança das manifestações e práticas corporais culturalmente construídas pelo seu meio social. Portanto, optamos pelo movimento corporal da criança, que deverá ser compreendido no âmbito da educação infantil, tanto como um meio para o seu desenvolvimento físico-motor, como para a compreensão, expressão e comunicação dos significados presentes no contexto sociocultural em que se encontra.

Com base no pressuposto de que na pequena infância o corpo em movimento constitui a matriz básica da aprendizagem, propomos a organização pedagógica do movimento corporal na educação infantil em torno de três eixos:

1. Autonomia e identidade corporal - implica aprendizagens que envolvem o corpo em movimento para o desenvolvimento físico-motor, proporcionando assim o domínio e a consciên- 
cia do corpo, condições necessárias para a autonomia e formação da identidade corporal infantil.

2. Socialização - é a compreensão dos movimentos do corpo como uma forma de linguagem, utilizada na e pela interação com o meio social.

3. Ampliação do conhecimento das práticas corporais infantis - envolve aprendizagens das práticas de movimentos corporais que constituem a cultura infantil, na qual a criança se encontra inserida.

O fazer pedagógico centrado nos movimentos do corpo infantil, o qual se constitui pela organização do espaço e pela disposição dos materiais educativos; a organização do tempo; a seleção de atividades pedagógicas e algumas atitudes básicas dos professores com as crianças pequenas deverão se organizar de modo a contemplar os três eixos propostos. Na integração entre estes observa-se a predominância de um sobre o outro, conforme as características e necessidades de cuidado/educação presentes em cada idade da pequena infância. Portanto, um eixo organizador não exclui o outro; eles se completam.

$\mathrm{Na}$ utilização desses eixos, o brincar se apresenta como um princípio pedagógico, pois na pequena infância esse comportamento propicia à criança condições de agir e compreender os significados presentes em seu cotidiano. Segundo Leontiev (1988, p. 122), "só no brinquedo as operações exigidas podem ser substituídas por outras e as condições do objeto podem ser substituídas por outras condições do objeto, com preservação do próprio conteúdo da ação". Portanto, é no brincar que a criança adapta a sua condição físicomotora e a do objeto e/ou situação às condições exigidas pela ação e, consequientemente, ela consegue experimentar, explorar e compreender os significados do seu meio.

Assim, brincando em atividades de intensa movimentação corporal, a criança desenvolverá os seus aspectos físico-motores e, ao mesmo tempo, poderá ser levada a entender que esses movimentos têm significados, pois se manifestam com o objetivo de expres- 
são e comunicação. Poderá entender, também, que os movimentos corporais se agrupam em diversas práticas. Na pequena infância essas práticas se organizam em jogos e brincadeiras que expressam o conhecimento a ser apropriado e construído pela criança pequena sobre o seu movimentar.

Ao ingressar na escola, independente da idade em que se encontra, a criança pequena traz consigo conhecimentos sobre o seu movimento corporal, apropriados e construídos nos diferentes espaços e relações em que vive. Portanto, a escola da pequena infância deve sistematizar e ampliar esses conhecimentos, não se esquecendo das características e necessidades de cuidado/educação corporais que constituem cada idade da infância. Desse modo, concluímos que o movimento corporal da criança não é somente uma necessidade para o seu desenvolvimento físico-motor, mas também um conhecimento que, traduzido em linguagem, contribui para a sua constituição como sujeito cultural.

\section{CONSIDERAÇÕES FINAIS PARA UM INÍCIO}

Diante do exposto, consideramos que este não é um momento de finalizar, mas sim de iniciar. Iniciar um aprofundamento teórico sobre as dúvidas, idéias e sínteses construídas durante o estudo. Iniciar um processo de interlocução e, se necessário, de reorientação das reflexões e proposições do texto mediante as considerações e críticas desencadeadas pela veiculação das mesmas. É necessário iniciar, também, um aprofundamento de estudos investigativos e discussões teóricas sobre a Educação Física nas atuais orientações e propostas curriculares para a educação infantil, principalmente, no Referencial curricular nacional para a educação infantil (Brasil, 1998), documento que está norteando as propostas pedagógicas de creches e pré-escolas no Brasil.

Para complementar, ressaltamos a necessidade dos adotar, em conjunto com a área da educação, discussões de caráter políticopedagógico sobre a formação dos educadores da infância - dentro de uma concepção de educação infantil - que valorizem o movimento corporal da criança no seu processo de apropriação da cultura e na construção do seu pensamento. Essa mobilização permitiria

118 GARANHANI, M. C. A educação física na escolarização da pequena infância 
um aprimoramento nos conhecimentos e nas orientações sobre os significados e implicações pedagógicas do movimento corporal da criança pequena no seu processo de escolarização.

\title{
Physical Education in the Education of Infants
}

\begin{abstract}
With the intention of offering reflections and propostions about Physical Education in the educational process of children aged 0-6, this study is organized in two distinct parts. In the first one, we develop reflections on children's body movements and their process of learning and building knowledge, based on the studies of Wallon. In the second part, we systematize propositions for a pedagogical approach for Physical Education in the infant education sphere.
\end{abstract}

KEY WORDS: Infant education - Body movement - School Physical Education.

\section{NOTAS}

1. O termo "educação infantil" será utilizado para se referir às instituições de atendimento a crianças de zero a seis anos, comumente conhecidas como creches e pré-escolas.

2. Machado (1998 e 1999); Kuhlmann (1999) e Cerisara (1999).

3. Segundo Wallon (1979), o desenvolvimento do homem depende de suas estruturas internas, biologicamente determinadas, e das relações que mantém com o meio social ao longo de sua existência, sendo que, entre os fatores de natureza biológica e os de natureza social, as fronteiras são tênues, havendo uma complexa relação de determinação recíproca.

4. Para Wallon, citado por Mahoney (2000), o desenvolvimento humano é regido por três leis reguladoras: 1) a alternância funcional: o movimento predominante ou é para dentro, para o conhecimento de si, ou é para fora, para o conhecimento do mundo exterior; 2) a predominância funcional: alternância na predominância de conjuntos diferentes a cada estágio e 3) a integração funcional: o avanço no desenvolvimento ocorre pela incorporação das conquistas passadas, que se reorganizam de forma a possibilitar o surgimento de atividades novas e mais complexas (uma relação de conjuntos funcionais hierarquizados). 
5. A imitação, para Wallon, "é, ao mesmo tempo, participação e desdobramento do ato, contradição que anuncia o nascimento da representação e revela sua importância para o desenvolvimento psicológico da criança" (Costa, 2000, p. 34).

6. Segundo Charlot (2000, p. 33), um sujeito é um ser humano, social e singular, que "se produz ele mesmo, e é produzido, através da educação".

7. Kishimoto (1995); Haddad e Johansson (1995); Faria (1995); Portugal (1997) e Brasil (1998).

8. Garanhani e Moro (2000).

\section{REFERÊNCIAS}

BRASIL. Ministério da Educação e do Desporto. Secretaria da Educação Fundamental. Referencial curricular nacional para a educação infantil. Brasília, 1998.

CERISARA, Ana Beatriz. Educar e cuidar: por onde anda a educação infantil? Perspectiva, Florianópolis, v. 17, n. especial, p. 11-21, jul./dez. 1999.

A educação infantil e as implicações pedagógicas do modelo histórico-cultural. Cadernos Cedes, Campinas, n. 35, jul. 2000.

CHARLOT, Bernard. Da relação com o saber: elementos para uma teoria. Porto Alegre: Artes Médicas Sul, 2000.

COSTA, Lúcia Helena F. Mendonça. Estágio sensório-motor e projetivo. In: MAHONEY, Abigail Alvarenga; ALMEIDA, Laurinda Ramalho. Henri Wallon: psicologia e educação. São Paulo: Loyola, 2000 .

FARIA, Ana Lúcia Goulart de. Da escola materna à escola da infância: a pré-escola na Itália hoje. Cadernos Cedes: Grandes Políticas para os Pequenos. Educação Infantil, Florianópolis, n. 37, p. 63100, 1995.

Educação pré-escolar e cultura: para uma pedagogia da educação infantil. São Paulo: Unicamp, Cortez, 1999. 
GARANHANI, Marynelma Camargo. A motricidade nos estudos da educação infantil no Brasil: uma análise da produção teórica na área da educação (1983-1998). Revista Paranaense de Educação Física, Curitiba, v. 1, n. 2, p. 31-39, nov. 2000.

GARANHANI, Marynelma Camargo; MORO, Vera Luzia. A escolarização do corpo infantil: uma compreensão do discurso pedagógico a partir do século XVII. Educar em Revista, Curitiba, n. 16, p. 109-119, 2000.

GRUPO DE ESTUDOS AMPLIADOS EM EDUCAÇÃO FÍSICA. Diretrizes curriculares para a Educação Física no ensino fundamental e na educação infantil da rede municipal de Florianópolis. Florianópolis: Nepef/UFSC-SME, 1996.

HADDAD, Lenira; JOHANSSON, Jan-Erik. A pré-escola sueca: a história de um sistema integrado de cuidado e educação. Cadernos Cedes: Grandes Políticas para os Pequenos. Educação Infantil, Florianópolis, n. 37, p. 45-61, 1995.

KISHIMOTO, Tizuko Morchida. A educação infantil no Japão. $C a-$ dernos Cedes: Grandes Políticas para os Pequenos. Educação Infantil, Florianópolis, n. 37, p. 23-43, 1995.

KUHLMANN JÚNIOR, Moysés. Educação Infantil e currículo. In: FARIA, Ana Lúcia Goulart; PALHARES, Marina Silveira. (Org.). Educação infantil pós-LDB: rumos e desafios. Campinas: Autores Associados, 1999.

LEONTIEV, Alexis N. Os princípios psicológicos da brincadeira préescolar. In: VYGOTSKY, Le Semenovich; LURIA, Alexander Romanovich; LEONTIEV, Alexis N. Linguagem, desenvolvimento e aprendizagem. São Paulo: Ícone, 1988.

MACHADO, Maria Lucia de A. Formação profissional para educação infantil: subsídios para idealização e implementação de projetos. 1998. Tese (Doutorado em Psicologia da Educação) - Pontifícia Universidade Católica de São Paulo, São Paulo.

Criança pequena, educação infantil e formação dos profissionais. Perspectiva, Florianópolis, v. 17, n. especial, p. 85-98, jul./dez. 1999. 
MAHONEY, Abigail Alvarenga. Introdução. In: MAHONEY, Abigail Alvarenga; ALMEIDA, Laurinda Ramalho. Henri Wallon: psicologia e educação. São Paulo: Loyola, 2000.

PORTUGAL. Ministério da Educação. Gabinete para a Expansão e Desenvolvimento da Educação Pré-Escolar. Orientações curriculares para a educação pré-escolar. Lisboa, 1997.

WALLON, Henri. Do acto ao pensamento. Ensaio de psicologia comparada. Lisboa: Moraes, 1942.

Importância do movimento no desenvolvimento psicológico da criança. In: WALLON, Henri. Psicologia e educação da criança. Lisboa: Vega, 1979.

WEREBE, Maria José Garcia; NADEL-BRULFERT, Jacqueline. Proposições para uma leitura de Wallon: em que aspectos sua obra permanece atual e original? In: WEREBE, Maria José Garcia; NADELBRULFERT, Jacqueline. Henri Wallon. São Paulo: Ática, 1999.

Recebido: Setembro de 2002 Aprovado: Novembro de 2002

Endereço para correspondência Marynelma Camargo Garanhani

Rua Coração de Maria, 92

BR 116 - Km 95

Jardim Botânico

Curitiba - Paraná

CEP 80215-370

E-mail: marynelma@avalon.sul.com.br

122 GARANHANI, M. C. A educação física na escolarização da pequena infância 